\title{
Caracterização hidrológica de nascentes de sub-bacias hidrográficas na região do Alto Rio Grande, MG
}

Lucas Alves da Silva ${ }^{1}$

Antônio Marciano da Silva²

Gilberto Coelho ${ }^{3}$

Leandro Campos Pinto 4

Eliete Nazaré Eduardo 5

\section{Resumo}

A Caracterização hidrológica de nascentes associadas à dinâmica local tem-se mostrado um instrumento importante na gestão dos recursos hídricos. 0 trabalho foi desenvolvido em duas sub-bacias hidrográficas: sub-bacia do Ribeirão Lavrinha e sub-bacia do Ribeirão Marcela, com ambientes fisiográficos distintos, inseridas na Unidade de Planejamento e Gestão de Recursos Hídricos do Alto Rio Grande (UPGRH-GD1) do Estado de Minas Gerais. Realizou-se a caracterização morfométrica das áreas de recarga de água, a modelagem hidrológica das vazões e a quantificação do uso e ocupação do solo em dez nascentes das sub-bacias hidrográficas dos Ribeirões Lavrinha e Ribeirão Marcela, sendo cinco em cada sub-bacia. Verificou-se grande variabilidade espacial e temporal das vazões das nascentes durante o ano de 2008. As duas sub-bacias hidrográficas monitoradas apresentaram grande diferença em termos de produção de água em suas nascentes, podendo estas diferenças ser atribuídas ao regime pluviométrico de cada localidade.

Palavras-chave: Manejo de bacias hidrográficas. Morfometria. SIG.

\section{Introdução}

A água é um recurso natural de valor inestimável, sendo vital para qualquer atividade humana, além de ser estratégica para o desenvolvimento econômico. Entretanto, a intervenção humana de maneira exploratória e inconsequente alteram a sua dinâmica dentro do espaço territorial das bacias hidrográficas, especificamente nas áreas de recarga das nascentes (MENEZES et al., 2009; MELLO; SILVA, 2013). Neste contexto, a qualificação (PINTO et al., 2013) e a quantificação das águas dentro desses territórios servem de indicativos do grau de degradação de recursos naturais.

A produção de água de uma bacia hidrográfica está associada à relação entre as suas características físiográficas e os processos produzidos nesta, tal como infiltração, escoamento superficial e sub-superficial e evapotranspiração (ALVES; CASTRO, 2003). De acordo com Tonello et al. (2006), a área da bacia hidrográfica influencia diretamente a quantidade de água produzida como deflúvio,

1 Universidade Federal de Lavras, Departamento de Engenharia, professor. lucasas@deg.ufla.br.

2 Universidade Federal de Lavras, Departamento de Engenharia, professor visitante sênior nacional na UNIFAL (MG). marciano@deg.ufla.br.

3 Universidade Federal de Lavras, Departamento de Engenharia, professor. coelho@deg.ufla.br.

4 Universidade Federal de Lavras, Departamento de Ciência do Solo, doutor em Ciência do Solo. leandcampos@yahoo.com.br. Campus Universitário, UFLA/DCS. Caixa Postal 3037, Lavras - MG, CEP 37200-000.

5 Universidade Federal de Lavras, Departamento de Ciência do Solo, doutora em Ciência do Solo. elietenazare@gmail.com. 
entretanto, sua forma e cobertura vegetal atuam sobre a taxa de produção de água, bem como sobre a taxa de sedimentação. O conhecimento dos aspectos físicos e principalmente da morfologia de uma bacia torna-se indispensável para estudos que mostrem realmente sua dinâmica.

A caracterização fisiográfica de bacias hidrográficas, associada às suas disponibilidades hídricas, possibilita entender fenômenos passados, avaliar impactos ambientais e ações antrópicas na fase de escoamento superficial da água e elaborar correlações entre vazões e características fisiográficas (ALVES; CASTRO, 2003).

Diante do exposto, o objetivo deste trabalho foi compreender o comportamento hidrológico de áreas de recarga de dez nascentes de duas sub-bacias hidrográficas pela obtenção e análise das características morfométricas, do uso e ocupação do solo e da disponibilidade hídrica das áreas.

\section{Material e métodos}

O trabalho foi desenvolvido em duas sub-bacias hidrográficas: sub-bacia do Ribeirão Lavrinha (SRL) e sub-bacia do Ribeirão Marcela (SRM), com ambientes fisiográficos distintos, inseridas na Unidade de Planejamento e Gestão de Recursos Hídricos do Alto Rio Grande (UPGRH-GD1) do Estado de Minas Gerais (FIGURA 1).

Figura 1. Localização das sub-bacias hidrográficas do Ribeirão Lavrinha (SRL) e do Ribeirão Marcela (SRM).

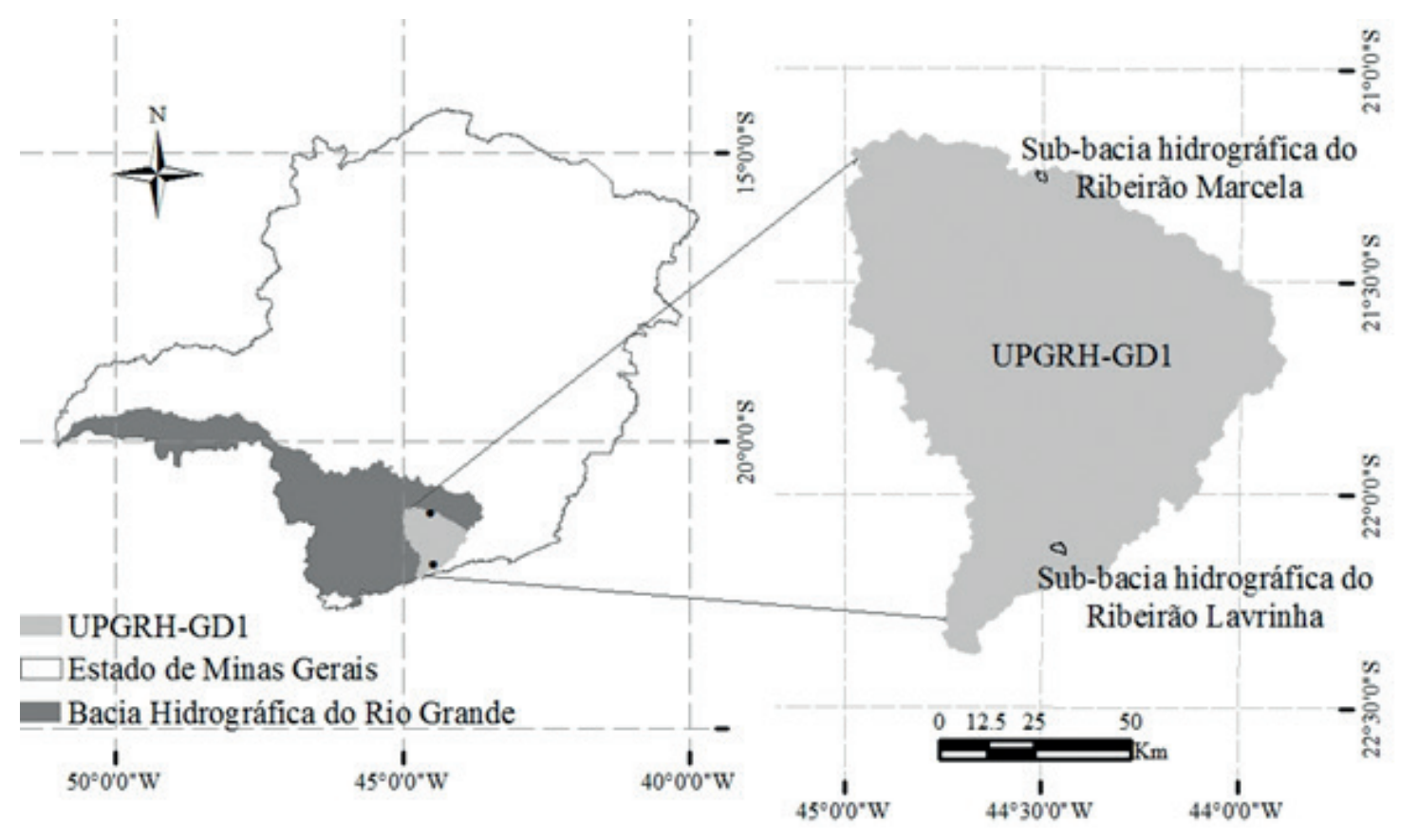

Fonte: Os autores (2008).

A SRL localiza-se no município de Bocaína de Minas (MG), com área de 676 ha, predominantemente com florestas nativas e pastagens, cujo curso d'água deságua diretamente no Rio Grande. O clima da região foi classificado em Cwb e Superúmido A, com base em metodologias de Köppen e Thorntwaite (MELLO et al., 2012). Os Cambissolos são os solos predominantes na área (MENEZES et al., 2009; PINTO et al., 2015; SKORUPA et al., 2017), cujas características são típicas da região da 
Serra da Mantiqueira, ou seja, solos pouco a moderadamente profundos, com relevo variando de ondulado a montanhoso (JUNQUEIRA JUNIOR, 2006). De acordo com registros da estação meteorológica localizada na área, há ocorrência de precipitação média anual de $1.860 \mathrm{~mm}$, temperatura média anual de $17,5^{\circ} \mathrm{C}$, cujos valores máximos e mínimos diários foram de 32 e 2,7 ${ }^{\circ} \mathrm{C}$ respectivamente, ocorrendo geadas anualmente.

A SRM localiza-se no município de Nazareno (MG), com área de 470 ha, predominantemente com Latossolos e agricultura tecnificada, cujo dreno principal, o Ribeirão Marcela, é afluente do Ribeirão da Jaguara que deságua no reservatório da Usina Hidrelétrica de Camargos/Companhia Energética de Minas Gerais (CEMIG). A região possui clima do tipo Cwa pela classificação Köppen, caracterizado como temperado, com verões quentes e úmidos e invernos secos (GOMES et al., 2007). Baseado em registros da estação meteorológica localizada na área, a precipitação média anual é de $1.300 \mathrm{~mm}$, com temperatura média anual de $19,7^{\circ} \mathrm{C}$, variando entre a máxima diária de $36,2^{\circ} \mathrm{C}$ e a mínima diária de $2,6^{\circ} \mathrm{C}$.

A seleção das 10 nascentes representativas nas duas sub-bacias hidrográficas baseou-se na condição de estarem sobre uma mesma unidade pedológica e possuírem diferentes ocupações do solo nas áreas de recarga, sendo denominadas como: nascentes L1; L2; L3; L4 e L5, para a sub-bacia do Ribeirão Lavrinha (SRL); nascentes M1; M2; M3; M4 e M5, para a sub-bacia do Ribeirão Marcela (SRM) (FIGURA 2).

Figura 2. Mapa de declividade das sub-bacias e a localização das nascentes avaliadas (L1, L2, L3, L4 e L5 Nascentes do Ribeirão Lavrinha (SRL) (A) e M1, M2, M3, M4 e M5 - Nascentes do Ribeirão Marcela (SRM) (B)).
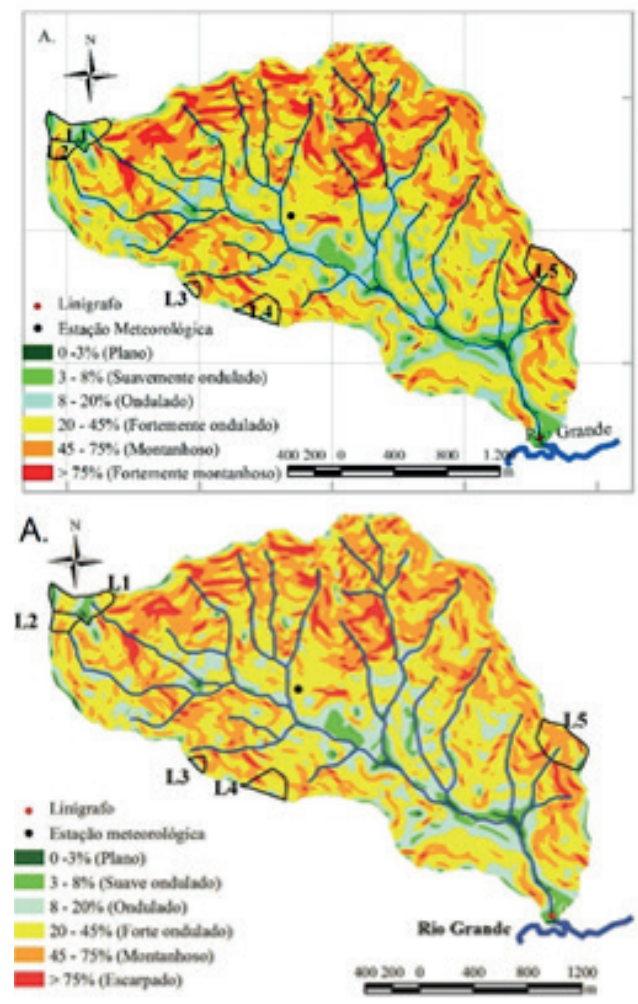
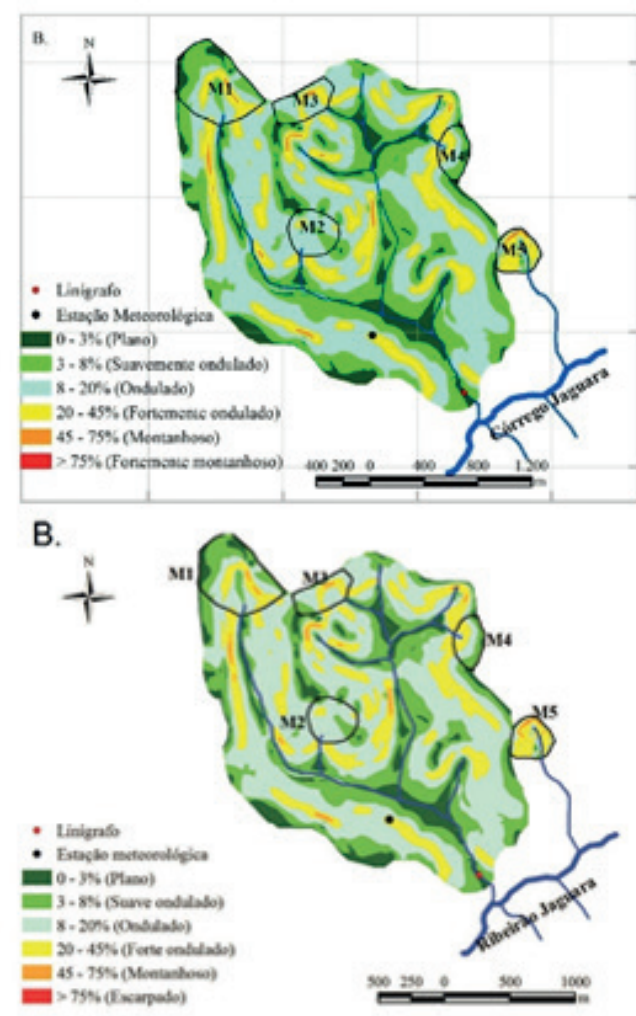

Fonte: Os autores (2008). 
Para delimitação das sub-bacias, foram utilizadas as cartas topográficas vetoriais do mapeamento sistemático publicadas pelo Instituto Brasileiro de Geografia e Estatística (IBGE), na escala 1:50.000. Foi realizada a interpolação linear entre os valores altimétricos das curvas de nível e os pontos cotados das cartas do IBGE. Posteriormente à interpolação, deu-se início à eliminação das distorções da grade de interpolação, que consiste na correção da imagem gerada por meio do preenchimento das depressões espúrias ou eliminação de picos gerados por erros na interpolação, para gerar o Modelo Digital de Elevação (MDEHC). A partir do MDEHC e de ferramentas específicas do software ArcGIS ${ }^{\circledR}$ version 9.2, foi possível delimitar automaticamente as sub-bacias hidrográficas e as áreas de recarga das nascentes avaliadas.

Para cada área de recarga, foi confeccionado um mapa de uso e ocupação do solo com base em um levantamento topográfico expedido feito com um receptor GPS modelo 76CSx marca Garmin, exceto nas nascentes L1, L5, M3 e M5, onde o mapa foi feito a partir de um levantamento topográfico planialtimétrico georreferenciado.

Na Tabela 1, estão apresentados os parâmetros morfométricos utilizados na caracterização das áreas de recarga das nascentes obtidos com base nas informações de Mello e Silva (2013), sendo realizados também com auxílio do software ArcGIS ${ }^{\circledR}$ versão 9.2.

Tabela 1. Parâmetros morfométricos para as áreas de recarga das nascentes.

\begin{tabular}{cc}
\hline \multicolumn{3}{c}{ Características morfométricas } \\
\hline Área $(\mathrm{A})$ & Fator de forma $\left(\mathrm{K}_{\mathrm{f}}\right)$ \\
Perímetro $(\mathrm{P})$ & Índice de conformação $\left(\mathrm{I}_{\mathrm{c}}\right)$ \\
Coeficiente de compacidade $\left(\mathrm{K}_{\mathrm{c}}\right)$ & \\
\hline \multicolumn{1}{c}{ Características do relevo } \\
\hline Altitude máxima $\left(\mathrm{E}_{\operatorname{máx}}\right)$ & Declividade máxima $\left(\mathrm{I}_{\text {máx }}\right)$ \\
Altitude média $(\overline{\mathrm{E}})$ & Declividade média $\left(\mathrm{I}_{\%}\right)$ \\
Altitude mediana $\left(\mathrm{E}_{\text {med }}\right)$ & Declividade mediana $\left(\mathrm{I}_{\text {med }}\right)$ \\
Altitude mínima $\left(\mathrm{E}_{\min }\right)$ & Declividade mínima $\left(\mathrm{I}_{\min }\right)$ \\
\hline
\end{tabular}

Fonte: Os autores (2008).

As vazões das nascentes foram monitoradas mensalmente de abril a novembro de 2008, para compor a base de dados deste trabalho, exceto as nascentes L1, L5, M3 e M5 para as quais a frequência de monitoramento foi quinzenal e o período de monitoramento foi de fevereiro a novembro de 2008. As vazões foram determinadas utilizando medidor de vazão sob regime crítico com calha modelo WSC Flume. A vazão da nascente L3 foi quantificada pelo método direto em três repetições empregando-se recipiente calibrado.

O intuito foi avaliar a capacidade de produção de água no período de tempo observado para determinada condição de uso e ocupação de solo, associando os parâmetros morfométricos e de relevo da área de recarga. O deflúvio quantificado no período de depleção do aquífero (período de seca) representa o volume de água subterrânea que foi drenado, em que a comparação em termos de produção de água foi realizada utilizando o conceito de rendimento específico, ou seja, vazão por unidade de área $\left(\mathrm{L}^{3} \mathrm{~T}^{-1} \mathrm{~L}^{-2}\right)$. Adicionalmente com as vazões médias mensais das nascentes, foi possível determinar o rendimento específico (RE) das nascentes, associando com a precipitação mensal. Devido à variabilidade espacial da precipitação, para que sua quantificação fosse mais representativa, 
foi instalado um pluviômetro conectado a um reservatório onde a quantificação do total precipitado foi feita com frequência quinzenal.

Com aos dados de vazão, ajustou-se um modelo exponencial conforme a "Fórmula de Maillet" (DEWANDEL et al., 2003) (EQUAÇÃO 1), para representar o comportamento temporal da vazão das nascentes, sendo o ajuste feito conforme o método de Newton Raphson, utilizando-se de forma complementar o coeficiente de determinação $\left(R^{2}\right)$ para verificação da qualidade do ajuste. Por este modelo apresentar aplicabilidade apenas em condições de depleção, geraram-se gráficos das vazões em função do tempo (sendo o tempo contado a partir do primeiro dia de monitoramento da vazão, ou seja, $t_{0}$ correspondendo $a_{\mathrm{t} 0}$ ) para identificação do período de depleção, para posterior modelagem.

$$
\mathrm{Q}_{\mathrm{t}}=\mathrm{Q}_{\mathrm{t} 0} \cdot \exp ^{(-\alpha \cdot \mathrm{t})}
$$

em que: $Q_{t}$ - vazão da nascentes em um instante $t\left(L^{-1}\right) ; Q_{t 0}$ - vazão da nascente no primeiro dia de monitoramento $\left(\mathrm{L} \mathrm{s}^{-1}\right) ; \alpha$ - coeficiente de recessão, representando a taxa de decaimento da vazão com o tempo (dia-1 ${ }^{-1}$, e t intervalo de tempo decorrido entre $t_{0}$ e $t$ (dias).

Integrando-se a Equação 1, obtém-se o deflúvio em volume, no período de análise, conforme indicado na Equação 2.

$$
\mathrm{VE}=86400 \cdot \frac{1}{\alpha} \cdot \mathrm{Q}_{\mathrm{t} 0} \cdot\left(1-\exp ^{-\alpha \cdot \mathrm{t}}\right)
$$

em que: VE - deflúvio superficial ( $L$ ); $\alpha$ - coeficiente de recessão (dia-1); $Q_{\text {to }}$ - vazão da nascente no primeiro dia do monitoramento $\left(L \cdot \mathrm{S}^{-1}\right)$ e $t$ - intervalo de tempo decorrido entre $t_{0}$ e $t$ (dia).

\section{Resultados e discussão}

\section{Caracterização geral das nascentes}

Em termos de regime de escoamento, todas as nascentes avaliadas apresentaram-se como sendo perenes (CASTRO; LOPES, 2001). As nascentes L1, L2, L3 e L4 foram consideradas pontuais (DAVIDE et al., 2002) e as demais classificadas como difusas. Devido à grande variabilidade das vazões ao longo do ano, Junqueira Júnior (2006) avaliando o escoamento destas mesmas nascentes, enquadrou-as como sendo freáticas.

Em geral, observou-se em todas as nascentes alguma forma de intervenção nas características físicas das áreas de preservação permanente (APPs). Durante as etapas de campo, pode-se perceber que as principais e mais frequentes formas de intervenção constituem-se na utilização destas áreas para pastagem e dessedentação do gado (sendo caracterizado pela presença do pisoteio e estrume) e a substituição da cobertura do solo por pastagem sem práticas de conservação de solo.

Caracterização morfométrica e do relevo das áreas de recarga das nascentes

A Tabela 2 apresenta os resultados numéricos dos parâmetros morfométricos e das características de relevo das áreas de recarga das nascentes avaliadas. 
Tabela 2. Resultados numéricos dos parâmetros morfométricos das áreas de recarga das nascentes avaliadas ${ }^{1}$.

\begin{tabular}{|c|c|c|c|c|c|c|c|c|c|c|}
\hline Nascentes & L1 & L2 & L3 & L4 & L5 & M1 & M2 & M3 & M4 & M5 \\
\hline \multicolumn{11}{|c|}{ Características morfométricas } \\
\hline A (ha) & 7,24 & 2,43 & 0,87 & 5,14 & 8,74 & 26,37 & 10,47 & 9,14 & 7,2 & 8,45 \\
\hline$P(m)$ & 1326,7 & 650,8 & 403,4 & 1008,8 & 1513,2 & 1965,8 & 1169,7 & 1248,6 & 1052 & 1073,9 \\
\hline Kc & 1,38 & 1,17 & 1,21 & 1,25 & 1,43 & 1,07 & 1,01 & 1,16 & 1,1 & 1,03 \\
\hline Kf & 0,38 & 0,68 & 1,01 & 1,1 & 1,27 & 0,65 & 0,88 & 1,48 & 1,25 & 0,76 \\
\hline IC & 0,4 & 0,61 & 0,98 & 1,07 & 1,23 & 0,63 & 0,82 & 1,85 & 1,16 & 0,73 \\
\hline \multicolumn{11}{|c|}{ Características do relevo } \\
\hline $\mathrm{E}_{\text {máx }}(\mathrm{m})$ & 1707,5 & 1680,6 & 1510 & 1436,5 & 1394,6 & 1059,2 & 1041,4 & 1059,6 & 1050 & 1054,5 \\
\hline$\overline{\mathrm{E}}(\mathrm{m})$ & 1668,4 & 1644,6 & 1499,3 & 1384,3 & 1321,6 & 1035,4 & 1021,5 & 1035,2 & 1037,8 & 1026,8 \\
\hline $\mathrm{E}_{\text {med }}(\mathrm{m})$ & 1666,7 & 1643,1 & 1502,6 & 1385,6 & 1322,5 & 1040,8 & 1022,4 & 1037 & 1040,9 & 1026,6 \\
\hline $\mathrm{E}_{\min }(\mathrm{m})$ & 1627,6 & 1610,3 & 1470,2 & 1334,4 & 1242,9 & 998,8 & 991,9 & 1004,4 & 1009,8 & 998,1 \\
\hline$I_{\text {máx }}(\%)$ & $218,560,0$ & 70,3 & 86,5 & 82,5 & $148,572,0$ & 58 & 22,5 & 72,4 & 35,2 & $285,333,5$ \\
\hline $\mathrm{I}_{\%}(\%)$ & 28,7 & 33,9 & 38,5 & 37,1 & 54,2 & 12,1 & 13,2 & 17 & 13 & 25,4 \\
\hline $\mathrm{I}_{\text {med }}(\%)$ & 28,2 & 32,4 & 30,8 & 37,2 & 55 & 8,7 & 14,3 & 15,6 & 10,9 & 24,5 \\
\hline $\mathrm{I}_{\text {min }}(\%)$ & 0,5 & 3,5 & 3,3 & 1,8 & 0,5 & 0,1 & 0,3 & 0,5 & 0,1 & 0,4 \\
\hline
\end{tabular}

${ }^{1} \mathrm{~A}$ - área; $\mathrm{P}$ - perímetro; $\mathrm{Kc}$ - coeficiente de compacidade; $\mathrm{Kf}$ - fator de forma; Ic - índice de conformação; Emáx, Ē, Emed e Emín - altitude máxima, média, mediana e mínima respectivamente; e Imáx, I\%, Imed e Imín - declividade máxima, média, mediana e mínima, respectivamente.

Fonte: Os autores (2009).

Utilizando a interpretação de Mello e Silva (2013), em termos de coeficiente de compacidade (Kc), todas as áreas de recarga apresentaram tendência à ocorrência de enchentes, em que especificamente as áreas L2, L3, L4, M1, M2, M3, M4 e M5 apresentaram alta propensão a grandes cheias $(1 \leq \mathrm{Kc}<1,25)$, enquanto as áreas L1 e L5 apresentaram tendência mediana $(1,25 \leq \mathrm{Kc}$ $<1,50)$. Com relação ao fator de forma $(\mathrm{Kf})$, todas as áreas apresentaram tendência à ocorrência de enchentes, exceto a área relativa à nascente $\mathrm{L} 1(\mathrm{Kf}<0,5)$, onde especificamente as áreas $\mathrm{L3}, \mathrm{L} 4$, L5, M2, M3, M4 e M5 apresentam-se sujeitas a cheias $(0,75<\mathrm{Kf} \leq 1)$, enquanto as áreas L2 e M1 apresentaram tendência mediana $(0,50 \leq \mathrm{Kf}<0,75)$. Em se tratando de propensão à ocorrência de cheias, o coeficiente de compacidade indica que a área de recarga que possui a menor propensão trata-se da área L1 (Ic mais distante de 1) e adicionalmente a que apresenta maior propensão refere-se à área L3 (Ic mais próximo de 1). Como os índices são complementares, o coeficiente de compacidade expressa a tendência de enchente e os outros expressam a dimensão desta, portanto, pode-se concluir que apenas a área de recarga L1 não apresenta tendência à ocorrência de enchentes.

Em termos de altitude, as áreas de recarga de nascentes da SRL apresentam variação de $1.242,9$ a $1.707,5 \mathrm{~m}$, enquanto que áreas de recarga de nascentes da SRM apresentam variação de 991,9 a 1.059,6 m, resultando em uma diferença de 500 m. De maneira geral, pode-se inferir que as áreas de recarga da SRL possuem maior propensão à ocorrência de menores temperaturas e maiores índices pluviométricos (MELLO et al., 2012), uma vez que a área dessa sub-bacia é formada predominantemente com florestas nativas e pastagens e apresentam registros pluviométricos de $1.860 \mathrm{~mm}$ de média anual e potencial de erosividade de chuva classificado como "muito forte" (MELLO et al., 2012). 
A declividade das áreas de recarga das nascentes tem uma relação importante e complexa com a infiltração, o escoamento superficial, a umidade do solo e a contribuição de água subterrânea ao escoamento do curso d'água. Tem relação direta com o tempo de oportunidade para que a precipitação possa vir a infiltrar, percolar e consequentemente abastecer os aquíferos subterrâneos. Áreas com declividades elevadas aceleram as enxurradas e dificultam a infiltração de água no solo. Assim, verificou-se que as declividades médias das áreas de recarga das nascentes estudadas variam na SRL de 28,7 a 54,2\% e na SRM variam de 12,1 a 25,4\%. Considerando constantes as características de uso e ocupação do solo, classe de solo e intensidade das chuvas, as áreas da SRL possuem maior predisposição à ocorrência de maiores índices de escoamento superficial, que por sua vez está associado à maior suscetibilidade à erosão dos solos.

Analisando-se conjuntamente relevo e cobertura vegetal, pode-se inferir que as condições do ponto de vista ambiental encontradas nas nascentes da SRL são preocupantes, pois a cobertura vegetal de Mata Atlântica vem sendo substituída por pastagem e este fato, aliado a uma situação de elevadas declividades e o predomínio de Cambissolos, favorecerá as perdas de água e solo.

Com relação às áreas de recarga da SRM, apesar de existir nelas uma agricultura mais tecnificada e intensiva em Latossolo (GOMES et al., 2007), devido ao relevo mais suave, há menor predisposição para perdas de água e solo.

\section{Uso e ocupação do solo das áreas de recarga}

As Tabelas 3 e 4 apresentam os percentuais de uso e ocupação das áreas de recarga da SRL e SRM, respectivamente.

Tabela 3. Distribuição percentual de uso e ocupação das áreas de recarga do Ribeirão Lavrinha.

\begin{tabular}{|c|c|c|}
\hline Nascente & Descrição de uso e ocupação & Observações \\
\hline \multirow{3}{*}{ L1 } & Pastagem - 92,9\% & \\
\hline & Samambaia - 6,9\% & Nascente explorada para dessedentação de gado \\
\hline & Mata $-0,2 \%$ & \\
\hline \multirow{2}{*}{ L2 } & Mata nativa $-67,1 \%$ & \multirow{2}{*}{ Aumento de área com pastagem } \\
\hline & Pastagem - 32,9\% & \\
\hline \multirow{2}{*}{ L3 } & Pastagem - 99,0\% & \multirow{2}{*}{$\begin{array}{l}\text { Área com indícios de queimadas e desvio do } \\
\text { tributário do curso principal }\end{array}$} \\
\hline & Pequenos arbustos - $1,0 \%$ & \\
\hline \multirow{3}{*}{ L4 } & Pastagem - 45,4\% & \multirow{3}{*}{$\begin{array}{c}\text { Implantação de área com eucalipto de forma } \\
\text { irregular }\end{array}$} \\
\hline & Mata nativa - $31,4 \%$ & \\
\hline & Eucalipto - 23,2\% & \\
\hline \multirow{4}{*}{ L5 } & Pastagem - 68,7\% & \multirow{4}{*}{$\begin{array}{l}\text { Exploração intensiva da pecuária (curso d'água } \\
\text { utilizado como bebedouro) }\end{array}$} \\
\hline & Samambaia - 28,7\% & \\
\hline & Mata nativa $-2,1 \%$ & \\
\hline & Brejo - 0,5\% & \\
\hline
\end{tabular}

Fonte: Os autores (2009). 
Tabela 4. Distribuição percentual de uso e ocupação das áreas de recarga do Ribeirão Marcela (SRM).

\begin{tabular}{|c|c|c|}
\hline Nascente & Descrição de uso e ocupação & Observações \\
\hline \multirow{5}{*}{ M1 } & Culturas anuais - $65,5 \%$ & \multirow{5}{*}{$\begin{array}{l}\text { Presença de gado na área, com queimadas } \\
\text { ocorrendo no período seco do ano }\end{array}$} \\
\hline & Outros (rodovia e estradas vicinais) - 13,9\% & \\
\hline & Vegetação em regeneração - 8,4\% & \\
\hline & Mata nativa $-7,2 \%$ & \\
\hline & Área de várzea - 4,9\% & \\
\hline \multirow{4}{*}{ M2 } & Culturas anuais - $45 \%$ & \multirow{4}{*}{$\begin{array}{l}\text { Presença de gado em períodos anteriores à } \\
\text { implantação das culturas }\end{array}$} \\
\hline & Vegetação em regeneração - 42,6\% & \\
\hline & Mata nativa - $10,1 \%$ & \\
\hline & Outros (estradas vicinais) - 2,3\% & \\
\hline \multirow{5}{*}{ M3 } & Pastagem - 66,7\% & \multirow{5}{*}{$\begin{array}{l}\text { Inexistência de proteção nos locais de } \\
\text { afloramento d'água, sendo utilizado para } \\
\text { dessedentação de animais }\end{array}$} \\
\hline & Culturas anuais - $22,4 \%$ & \\
\hline & Outros (rodovia) - 7,8\% & \\
\hline & Área de várzea - 2,9\% & \\
\hline & Mata nativa $-0,2 \%$ & \\
\hline \multirow{3}{*}{ M4 } & Vegetação em regeneração - 47,2\% & \multirow{3}{*}{ Existe proteção contra circulação do gado } \\
\hline & Pastagem - 37,1\% & \\
\hline & Mata nativa - $15,7 \%$ & \\
\hline \multirow{5}{*}{ M5 } & Mata nativa - $48,5 \%$ & \multirow{5}{*}{$\begin{array}{l}\text { Inexistência de proteção nos locais de } \\
\text { afloramento d'água, sendo utilizado para } \\
\text { dessedentação de animais }\end{array}$} \\
\hline & Pastagem - 33,2\% & \\
\hline & Culturas anuais - $10,2 \%$ & \\
\hline & Área de várzea - 6,0\% & \\
\hline & Outros (estradas vicinais) $-2,2 \%$ & \\
\hline
\end{tabular}

Fonte: Os autores (2009).

A nascente $\mathrm{L} 2$ foi a que apresentou melhores condições do ponto de vista ambiental, apresentando o maior percentual de mata nativa $(67,1 \%)$ e sem intervenções diretas no ponto de afloramento d'água devido às dificuldades de acessibilidade local. De acordo com Ribeiro e Freitas (2010), as matas nativas da Serra da Mantiqueira estão inseridas em um agromosaico com diferentes usos do solo, atualmente, os remanescentes de florestas ocorrem nas áreas de topo e em altas elevações, que são áreas inadequadas para a agricultura. Entretanto, observou-se avanço na substituição da Mata Atlântica por áreas de pastagem implantadas sem práticas de conservação do solo, fato que poderá favorecer o escoamento superficial direto e potencializar as perdas de água e solo (BESKOW et al., 2009).

Para a SRM, a área de recarga da nascente M5 foi a que apresentou as melhores condições de cobertura vegetal, sendo que em todas as áreas de recargas analisadas nesta sub-bacia, existiu alguma forma de intervenção direta nas APPs e nos locais de afloramento d'água.

As áreas de recarga de nascentes da SRM encontram-se mais antropizadas que as da SRL. Junqueira Júnior (2006) salientou que a cobertura vegetal em áreas de nascentes é um fator determinante no suprimento de água para os aquíferos que, de acordo com Menezes et al. (2009), funcionam como esponjas, absorvendo grande parte da água das chuvas e liberando-as lentamente para o solo, proporcionando menor variação temporal das vazões dos cursos d'água. 


\section{Modelagem das vazões das nascentes}

A Tabela 5 apresenta as equações das vazões ajustadas ao modelo exponencial "Fórmula de Maillet" das nascentes das sub-bacias hidrográficas avaliadas.

Tabela 5. Equações ajustadas aos dados de vazão das nascentes do Ribeirão Lavrinha e Ribeirão Marcela.

\begin{tabular}{|c|c|c|c|c|c|}
\hline Sub-bacia & Nascentes & $Q_{t_{0}}\left(L^{-1}\right)$ & $\alpha\left(\mathrm{dia}^{-1}\right)$ & Equação & $\mathbf{R}^{2}$ \\
\hline \multirow{5}{*}{ Ribeirão Lavrinha } & L1 & 2,07 & 0,0052 & $\mathrm{Q}_{t}=2,24 \cdot \mathrm{e}^{-0,0052 . t}$ & 0,95 \\
\hline & L2 & 0,89 & 0,0065 & $\mathrm{Q}_{t}=0,84 \cdot \mathrm{e}^{-0,0065 \cdot t}$ & 0,95 \\
\hline & L3 & 0,11 & 0,0130 & $Q_{t}=0,11 \cdot e^{-0,0130 . t}$ & 0,98 \\
\hline & L4 & 3,40 & 0,0074 & $\mathrm{Q}_{t}=3,40 \cdot \mathrm{e}^{-0,0074 . t}$ & 0,99 \\
\hline & L5 & 1,36 & 0,0053 & $\mathrm{Q}_{t}=1,70 \cdot \mathrm{e}^{-0,0053 . t}$ & 0,96 \\
\hline \multirow{5}{*}{$\begin{array}{l}\text { Ribeirão } \\
\text { Marcela }\end{array}$} & M1 & 2,78 & 0,0070 & $Q_{t}=2,78 \cdot e^{-0,0070 . t}$ & 0,95 \\
\hline & M2 & 0,64 & 0,0150 & $Q_{t}=0,64 \cdot e^{-0,0150 . t}$ & 0,93 \\
\hline & M3 & 0,95 & 0,0026 & $\mathrm{Q}_{t}=1,06 \cdot \mathrm{e}^{-0,0026 . t}$ & 0,86 \\
\hline & M4 & 0,33 & 0,0048 & $\mathrm{Q}_{t}=0,33 \cdot \mathrm{e}^{-0,0048 . t}$ & 0,96 \\
\hline & M5 & 1,66 & 0,0089 & $Q_{t}=1,90 \cdot e^{-0,0089 . t}$ & 0,95 \\
\hline
\end{tabular}

Fonte: Os autores (2009).

Pode-se observar que os dados tiveram alto ajuste ao modelo exponencial proposto, verificado nos valores de coeficiente de determinação $\left(R^{2}\right)$.

Com o intuito de comparar os modelos obtidos, determinou-se o percentual de depleção da vazão de cada nascente, avaliado no mesmo intervalo de tempo, período de 05/04 a 25/10/2008 para SRL, período de 06/04 a 25/10/2008 para a SRM (Tabela 6).

Tabela 6. Decaimento percentual das vazões das nascentes monitoradas na SRL (período de 05/04 a 25/10/2008) e SRM (período de 06/04 a 25/10/2008) ${ }^{1}$.

\begin{tabular}{ccccc}
\hline Sub-bacia & Nascentes & $\mathbf{Q}_{\mathrm{to}}\left(\mathbf{L ~ s}^{-1}\right)$ & $\mathbf{Q}_{\mathrm{t} 1}\left(\mathbf{L ~ s}^{-1}\right)$ & $\left.\mathbf{( Q}_{\mathrm{to}}-\mathbf{Q}_{\mathrm{t} 1} / \mathbf{Q}_{\mathrm{to}}\right) \cdot \mathbf{1 0 0}(\%)$ \\
\hline \multirow{3}{*}{ Ribeirão Lavrinha } & $\mathrm{L} 1$ & 2,07 & 0,72 & 65,22 \\
& $\mathrm{~L} 2$ & 0,89 & 0,23 & 74,16 \\
& $\mathrm{~L} 3$ & 0,11 & 0,01 & 90,90 \\
& $\mathrm{~L} 4$ & 3,40 & 0,76 & 77,65 \\
Ribeirão Marcela & L5 & 1,36 & 0,46 & 66,18 \\
\hline & M1 & 2,78 & 0,68 & 75,54 \\
& M2 & 0,64 & 0,03 & 95,31 \\
& M4 & 0,95 & 0,56 & 41,05 \\
& M5 & 0,33 & 0,12 & 63,64 \\
\hline
\end{tabular}

${ }^{1} Q_{\text {to }}$ - vazões avaliadas no início da depleção (maior valor de vazão); $Q_{t 1}$ - vazões avaliadas no final da depleção (menor valor de vazão).

Fonte: Os autores (2009). 
Especificamente com relação às nascentes da $S R L$, observa-se que a maior diminuição da vazão ocorreu na nascente L3 (pastagem com declividade de 38,5\%), sendo seguida das nascentes L4 (pastagem, mata e eucalipto, com declividade de 37,1\%), L2 (pastagem e mata, com declividade de 33,9\%), L5 (pastagem com declividade de 54,2\%) e L1 (pastagem com declividade de 28,7\%). Com relação às nascentes da SRM, pode-se observar que a nascente M2 (regeneração natural, milho e mata, com declividade média de 13,2\%) foi a que apresentou maior diminuição da vazão, sendo acompanhada das nascentes M5 (mata, pastagem e milho, com declividade 25,4\%), M1 (milho, regeneração natural, mata e outros, com declividade média de 12,1\%), M4 (regeneração natural, pastagem e mata, com declividade média de 13,0\%) e M3 (pastagem e milho, com declividade média de $54,2 \%$ ).

De maneira geral, não foi possível identificar qual das características relacionadas (uso e ocupação ou declividade) causou maior interferência na manutenção vazão das nascentes ao longo do ano.

\section{Rendimento específico (RE) das nascentes}

A Figura 3 ilustra o comportamento temporal do RE das nascentes da SRL e SRM, associados aos eventos de precipitação mensal.

Verifica-se que existem relações importantes entre as condições de uso e ocupação do solo, característica topográfica e manejo do solo com o RE das nascentes, sendo a capacidade de produção d'água por unidade de área muito variável em conformidade com cada ambiente. Especificamente em relação à SRL, as áreas de recarga das nascentes compostas por mata (L2 e L4) apresentaram maiores valores de RE quando comparadas às áreas compostas por pastagem. Com relação às áreas de recarga da SRM, observou-se que as precipitações que ocorreram no período de fevereiro a novembro, na maioria dos casos, proporcionaram uma resposta rápida na elevação da capacidade de produção d'água pelas nascentes, o que pode ser explicado pelo fato de essa sub-bacia apresentar menores índices de declividade quando comparada à SRL, fato que proporciona melhores condições de recarga dos aquíferos subterrâneos ao longo do ano. 
Figura 3. Rendimento específico (RE) apresentado pelas nascentes na SRL (A) e SRM (B), no período de Fevereiro a Novembro de 2008.

A.

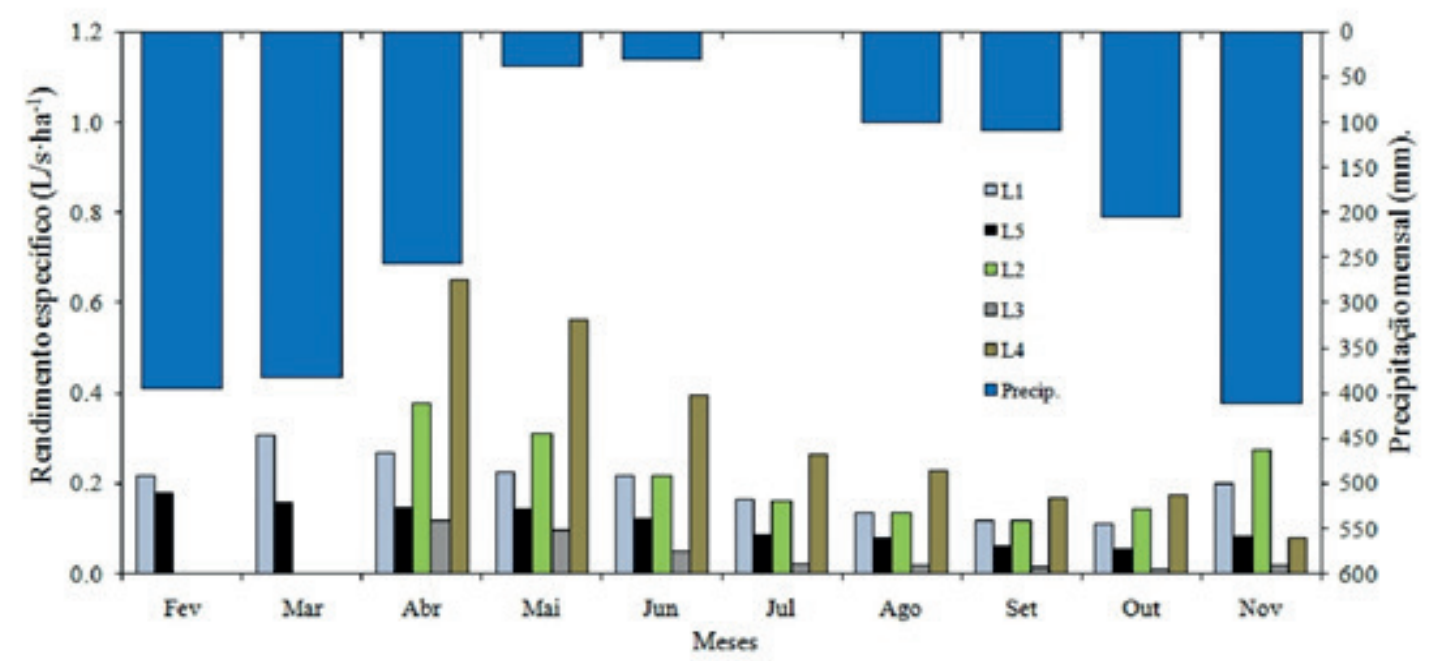

B.

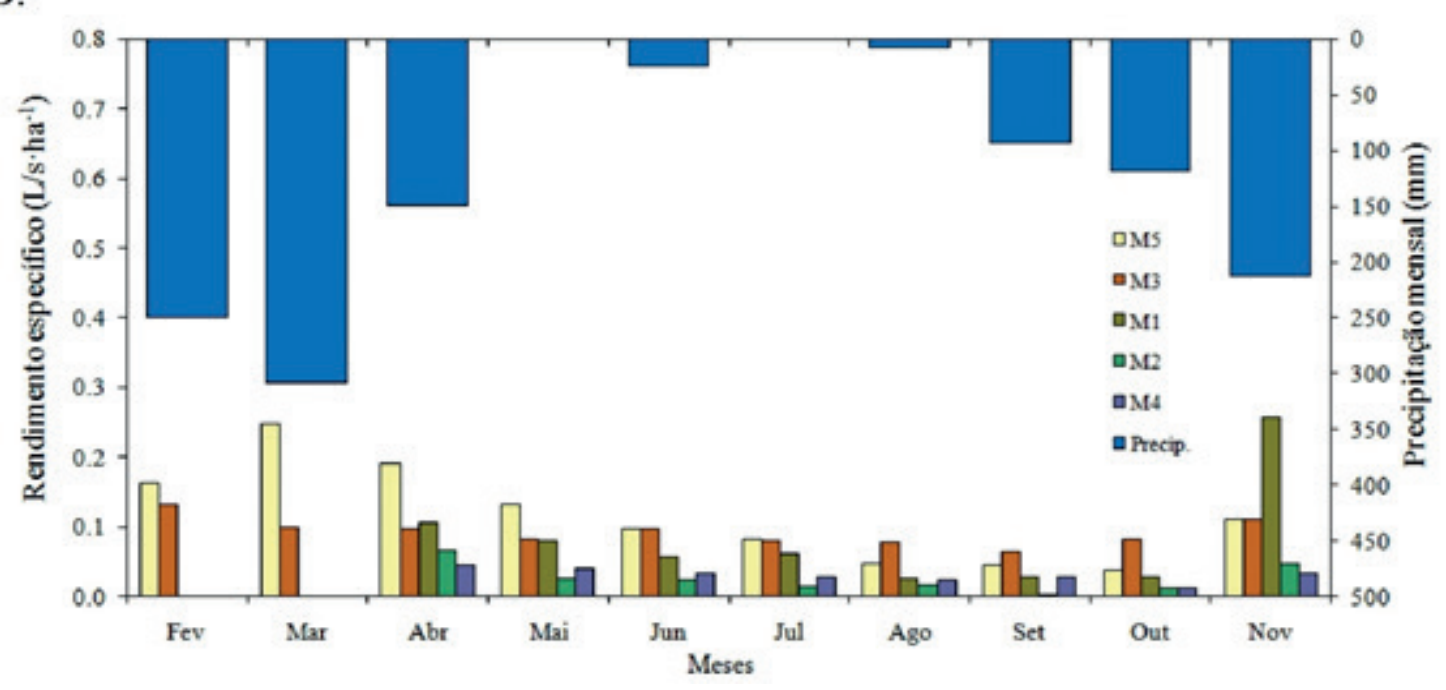

Fonte: Os autores (2009).

A resposta rápida ou lenta às precipitações na recuperação da capacidade de produção d'água pelas nascentes depende, principalmente, das condições iniciais de umidade do solo (ÁVILA; MELLO; SILVA, 2010; ÁVILA et al., 2014), da sua textura, estrutura, profundidade, cobertura vegetal, da intensidade das precipitações, das condições de relevo, das condições físico-hídricas do solo (MELLO et al., 2007; MELLO; SILVA, 2013), dentre outros, pois são estes os mecanismos que armazenam e distribuem a água vinda das precipitações.

\section{Deflúvio das nascentes}

A Tabela 7 apresenta o deflúvio total em volume $(\mathrm{L})$, lâmina $(\mathrm{mm})$ e a vazão média diária ( $\mathrm{L}$ dia $^{-1}$ ) para o período monitorado. 
Tabela 7. Deflúvio total em volume (L), lâmina (mm) e vazão média diária do período (L/dia) das nascentes monitoradas.

\begin{tabular}{ccccc}
\hline Sub-bacia hidrográfica & Nascente & Deflúvio (L) & Deflúvio (mm) & Vazão média diária (L dia-1) \\
\hline \multirow{6}{*}{ Ribeirão Lavrinha } & L1 & 25271540,29 & 349,2 & 115924,50 \\
& L2 & 8631310,79 & 355,8 & 42518,77 \\
& L3 & 655402,82 & 75,5 & 3228,59 \\
& L4 & 30857283,19 & 599,9 & 129652,45 \\
& L5 & 20196549,55 & 231,1 & 77381,42 \\
\hline \multirow{2}{*}{ Ribeirão Marcela } & M1 & 26064914,68 & 98,9 & 128398,59 \\
& M2 & 3401727,01 & 32,5 & 19438,44 \\
& M3 & 15159667,98 & 165,8 & 69860,22 \\
& M4 & 3710534,56 & 51,6 & 18100,17 \\
\hline
\end{tabular}

Fonte: Os autores (2009).

Pode-se observar que para a SRL, a área de recarga relativa à nascente $L 4$ (5,14 ha, composta por pastagem, mata nativa e eucaliptos) apresentou o maior valor de deflúvio (599,9 mm), enquanto o menor valor $(75,5 \mathrm{~mm})$ foi para a área relativa à nascente $\mathrm{L} 3(0,87 \mathrm{ha}$, composto por pastagem). Para a SRM, a área de recarga da nascente M5 (8,45 ha, composto por mata nativa, pastagem e milho) resultou no maior valor de deflúvio (183,4 mm), enquanto a área de recarga da nascente M2 (10,47 ha, composto por milho e regeneração natural) resultou no menor valor de deflúvio (32,5 mm).

Pinto et al. (2004) realizaram a caracterização das nascentes perenes da Bacia Hidrográfica do Ribeirão Santa Cruz e de suas áreas de recarga. Os autores concluíram que as maiores áreas de recarga não mostraram correlação com as maiores vazões das nascentes. Esses resultados mostram a importância da caracterização das nascentes para a compreensão dos fenômenos que ocorrem nelas.

De maneira geral, não foi possível observar relação entre as dimensões das áreas de recarga, o uso e ocupação do solo e a declividade dos terrenos, com o deflúvio anual das nascentes monitoradas. Entretanto, observou-se diferença em termos de produção de água das nascentes nas duas sub-bacias, que está relacionada à diferenciação do regime pluviométrico das regiões.

\section{Conclusões}

Verificou-se grande variabilidade espacial e temporal das vazões das nascentes ao longo do ano de 2008.

As duas sub-bacias hidrográficas monitoradas apresentaram grandes diferenças em termos de produção d'água em suas nascentes, podendo estas diferenças ser atribuídas ao regime pluviométrico de cada localidade. 


\title{
Hydrological characterization of watersheds in Alto Rio Grande region, Minas Gerais State
}

\begin{abstract}
Hydrology characterization of springs associated with the local dynamics has shown itself as an important tool for water resources management. This study was conducted at Lavrinha Creek Watershed and Marcela Creek Watershed located in Alto Rio Grande Basin, an environment with different physiographical conditions. These watersheds are inserted in the Planning Units for Management of Water Resources of Alto Rio Grande Basin (UPGRH-GD1) of Minas Gerais State. The morphometric characterization of recharge areas was performed as well as hydrological modeling of flow rates and land use maps, at 10 springs located inside Lavrinha and Marcela creeks' watersheds. High spatial and temporal variability of flow rate values were observed during the 2008 year. Both watersheds monitored revealed large difference on water production by their springs, being this difference attributed to the rainfall regime at each location.
\end{abstract}

Keywords: Watershed management. Morphometric characteristics. SIG.

\section{Referências}

ALVES, J. M. P.; CASTRO, P. T. A. Influência de feições geológicas na morfologia da bacia do Rio Tanque (MG) baseada no estudo de parâmetros morfométricos e análise de padrões de lineamentos. Revista Brasileira de Geociências, São Paulo, v.33, n. 2, p. 117-127, 2003. Disponível em: <http:// www.ppegeo.igc.usp.br/index.php/rbg/article/view/9821 >. Acesso em: 19 set. 2009.

ÁVILA, L. F.; MELLO, C. R.; SILVA, A. M. Continuidade e distribuição espacial da umidade do solo em bacia hidrográfica da Serra da Mantiqueira. Revista Brasileira de Engenharia Agrícola e Ambiental, v.14, n.12, p. 1257-1266, 2010. Disponível em: <http://www.scielo.br/pdf/rbeaa/v14n12/02. pdf $>$. Acesso em: 25 set. 2015.

ÁVILA, L. F.; MELLO, C. R.; PINTO, L. C.; SILVA, A. M. PARTIÇÃO DA PRECIPITAÇÃO PLUVIAL EM UMA MICROBACIA HIDROGRÁFICA OCUPADA POR MATA ATLÂNTICA NA SERRA DA MANTIQUEIRA, MG. Ciência Florestal, v.24, n.3, p. 583-595, 2014. Disponível em: <http://www. scielo.br/pdf/cflo/v24n3/0103-9954-cflo-24-03-00583.pdf>. Acesso em: 25 mar. 2015.

BESKOW, S.; MELLO, C. R.; NORTON, L. D. ; CURI, N.; VIOLA, M. R.; AVANZI, J. C. Soil erosion prediction in the Grande River Basin, Brazil, using distributed modeling. Catena, v.79, p. 49-59, 2009. Disponível em: <https://www.sciencedirect.com/science/article/pii/S0341816209001088>. Acesso em: 01 mar. 2011.

CASTRO, P.; LOPES, J. D. S. Recuperação e conservação de nascentes. Viçosa, MG: CPT, 2001. 84 p. DAVIDE, A. C.; PINTO, L. V. A.; MONNERAT, P. F.; BOTELHO, S. A. Nascente: o verdadeiro tesouro da propriedade rural: o que fazer para conservar as nascentes nas propriedades rurais. Lavras: UFLA/ CEMIG, 2002. 20 p. 
DEWANDEL, B.; LACHASSAGNE, P.; BAKALOWICZ, M.; WENG, P. H.; AL-MALKI, A. Evaluation of aquifer thickness by analysing recession hydrographs. Aplication to the Oman ophiolite had-rock aquifer. Journal of Hydrology, v. 274, p. 248-269, 2002. Disponível em: <https://www.sciencedirect. com/science/article/pii/S0022169402004183 >. Acesso em: 10 mar. 2008.

GOMES, N. M.; SILVA, A. M.; MELLO, C. R.; FARIA, M. A.; OLIVEIRA, P. M. Métodos de ajuste e modelos de semivariograma aplicados ao estudo da variabilidade espacial de atributos físico-hídricos do solo. Revista Brasileira de Ciência do Solo, v.31, p. 435-443, 2007. Disponível em: <http://www. scielo.br/pdf/rbcs/v31n3/a03v31n3.pdf>. Acesso em: 10 mar. 2009.

JUNQUEIRA JÚNIOR, J. A. Escoamento de nascentes associado à variabilidade espacial de atributos físicos e uso do solo em uma bacia hidrográfica de cabeceira do Rio Grande, MG. 2006. 84f. Dissertação (Mestrado) - Universidade de Lavras, Lavras, 2006. Disponível em:<http://repositorio.ufla.br/ bitstream/1/3365/1/DISSERTA\%C3\%87\%C3\%830_Escoamento\%20de\%20nascentes\%20associado\%20\%C3\%A0\%20variabilidade\%20espacial\%20de\%20atributos\%20f\%C3\%ADsicos\%20e\%20 uso\%20do\%20solo\%20em\%20uma\%20bacia\%20hidrogr\%C3\%A1fica\%20de\%20cabeceira... pdf>. Acesso em: 20 mar. 2009.

MELLO, C. R.; GOMES, N. M.; SILVA, A. M.; JUNQUEIRA JÚNIOR, J. A. Modelagem de atributos físico-hídricos do solo numa bacia hidrográfica da região do Alto Rio Grande, MG. Revista Brasileira de Ciência do Solo, v.31, p. 845-852, 2007. Disponível em: < http://www.scielo.br/pdf/rbcs/v31n5/ a02v31n5.pdf>. Acesso em: 23 abr. 2009.

MELLO, C. R.; NORTON, L. D.; CURI, N.; YANAGI, S. N. M. Sea surface temperature (SST) and rainfall erosivity in the Upper Grande River Basin, Southeast Brazil. Ciência e Agrotecnologia, v.36, p. 53-59, 2012. Disponível em: <http://www.scielo.br/pdf/cagro/v36n1/07.pdf >. Acesso em: 14 abr. 2014.

MELLO, C. R.; SILVA, A. M. Hidrologia: princípios e aplicações em sistemas agrícolas. Lavras: UFLA, 2013. p. 33-72.

MENEZES, M. D.; JUNQUEIRA JÚNIOR, J. A.; MELLO, C. R.; SILVA, A. M.; CURI, N.; MARQUES, J.J. Dinâmica hidrológica de duas nascentes, associada ao uso do solo, características pedológicas e atributos físico-hídricos na sub-bacia hidrográfica do Ribeirão Lavrinha - Serra da Mantiqueira (MG). Scientia Forestalis, v. 37, p. 175-184, 2009. Disponível em: <http://www.ipef.br/publicacoes/scientia/nr82/cap07.pdf>. Acesso em: 14 set. 2008.

PINTO, L. C.; MELLO, C. R.; FERREIRA, D. F.; ÁVILA, L. F. Water quality index in two land use situations in the Mantiqueira Range. Ciência e Agrotecnologia, v. 37, p. 338-342, 2013. Disponível em: <http://www.scielo.br/pdf/cagro/v37n4/v37n4a07.pdf>. Acesso em: 30 abr. 2014.

PINTO, L. C.; MELLO, C. R.; OWENS, P. R.; NORTON, L. D.; CURI, N. Role of Inceptisols in the hydrology of mountainous catchments in Southeastern Brazil. Journal of Hydrologic Engineering, v. 21, n. 2, p. 1-10, 2015. Disponível em: <https://ascelibrary.org/doi/10.1061/\%28ASCE\%29HE.1943-5584.0001275>. Acesso em: 22 abr. 2016.

PINTO, L. V. A.; BOTELHO, S. A.; DAVIDE, A. C.; FERREIRA, E. Estudo das nascentes da bacia hidrográfica do Ribeirão Santa Cruz, Lavras, MG. Scientia Forestalis, n.65, p.197-206, 2004. Disponível em: <http://www.ipef.br/publicacoes/scientia/nr65/cap19.pdf>. Acesso em: 05 dez. 2015. 
RIBEIRO, K. T.; FREITAS, L. Impactos potenciais das alterações no Código Florestal sobre a vegetação de campos rupestres e campos de altitude. Biota Neotropica, v.10, p. 239-246, 2010. Disponível em: <http://www.biotaneotropica.org.br/v10n4/pt/fullpaper?bn04310042010+pt>. Acesso em: 20 abr. 2013.

SKORUPA, A. L. A.; SILVA, S. H. G.; POGGERE, G. C.; TASSINARI, D.; PINTO, L. C.; ZINN, Y. L.; CURI, N. Similar soils but different soil-forming factors: converging evolution of Inceptisols in Brazil. Pedosphere, v. 27, p. 747-757, 2017. Disponível em: <https://www.sciencedirect.com/science/ article/pii/S1002016017604430>. Acesso em: 20 dez. 2017.

TONELLO, K. C.; DIAS, H. C. T.; SOUZA, A. L.; RIBEIRO, C. A. A. S.; LEITE, F. P. Morfometria da bacia hidrográfica da cachoeira das Pombas, Guanhães - MG. Revista Árvore, v. 30, p. 849-857, 2006. Disponível em: <http://www.scielo.br/pdf/rarv/v30n5/a19v30n5.pdf 16017604430>. Acesso em: 20 mar. 2008.

\section{Histórico editorial:}

Submetido em: 21/11/2016

Aceito em: 11/08/2017

Como citar:

$\underline{A B N T}$

SILVA, L. A. da; SILVA, A. M. da; COELHO, G.; PINTO, L. C.; EDUARDO, E. N. Caracterização hidrológica de nascentes de sub-bacias hidrográficas na região do Alto Rio Grande, MG. Revista Agrogeoambiental, Pouso Alegre, v. 10, n. 3, p. 105-119, jul./set. DOI: http://dx.doi.org/10.18406/2316-1817v10n320181143

\section{$\underline{A P A}$}

SILVA, L. A. da, SILVA, A. M. da, COELHO, G., PINTO, L. C. \& EDUARDO, E. N. (2018). Caracterização hidrológica de nascentes de sub-bacias hidrográficas na região do Alto Rio Grande, MG. Revista Agrogeoambiental, 10 (3), 105-119. DOI: http://dx.doi.org/10.18406/2316-1817v10n320181143

$\underline{\text { ISO }}$

SILVA, L. A. da; SILVA, A. M. da; COELHO, G.; PINTO, L. C. e EDUARDO, E. N. Caracterização hidrológica de nascentes de sub-bacias hidrográficas na região do Alto Rio Grande, MG. Revista Agrogeoambiental, 2018 , vol. 10, n. 3, pp. 105-119. Eissn 2316-1817. DOI: http://dx.doi.org/10.18406/2316-1817v10n320181143

\section{VANCOUVER}

Silva LA da, Silva AM da, Coelho G, Pinto LC, Eduardo EN. Caracterização hidrológica de nascentes de sub-bacias hidrográficas na região do Alto Rio Grande, MG. Rev agrogeoambiental. 2018. jul./set.; 10(3): 105-119. DOI: http://dx.doi.org/10.18406/2316-1817v10n320181143 


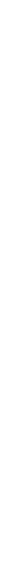

